\title{
An uncommon cause of Cushing's syndrome in a 70-year-old man
}

\author{
Kitty KT Cheung *, WY So, Alice PS Kong, Ronald CW Ma, KF Lee, Francis CC Chow
}

\section{A B S T R A C T}

Cushing's syndrome due to exogenous steroids is common, as about $1 \%$ of the general populations use exogenous steroids for various indications. Although endogenous Cushing's syndrome due to ectopic adrenocorticotropic hormone from a pancreatic neuroendocrine tumour is rare, a correct and early diagnosis is important. The diagnosis and management require high clinical acumen and collaboration between different specialists. We report a case of ectopic adrenocorticotropic hormone Cushing's syndrome due to pancreatic neuroendocrine tumour with liver metastasis. Early recognition by endocrinologists with timely surgical resection followed by referral to oncologists led to a favourable outcome for the patient up to 12 months after initial presentation.

\section{Hong Kong Med J 2014;20:335-8}

DOI: 10.12809/hkmj134158

${ }^{1}$ KKT Cheung *, MRCP, FHKAM (Medicine)

${ }^{1}$ WY So, FRCP, FHKAM (Medicine)

${ }^{1}$ APS Kong, FRCP, FHKAM (Medicine)

${ }^{1}$ RCW Ma, FRCP, FHKAM (Medicine)

${ }^{2}$ KF Lee, FRCSEd (Gen), FHKAM (Surgery)

${ }^{1}$ FCC Chow, FRCP, FHKAM (Medicine)

${ }^{1}$ Department of Medicine and Therapeutics

2 Department of Surgery

The Chinese University of Hong Kong, Prince of Wales Hospital, Shatin, Hong Kong

* Corresponding author: kittyktcheung@cuhk.edu.hk

\section{Case report}

In March 2013, a 70-year-old Chinese man presented with polyuria and polydipsia was diagnosed to have new-onset type 2 diabetes mellitus. He had suboptimal glycaemic control, and received multiple oral hypoglycaemic agents (OHAs). At the same time, he was noted to have bilateral lower limb pitting oedema and difficult to heal wounds over feet, as well as persistent hypokalaemia for which he was prescribed regular treatment with a potassium- sparing diuretic and oral potassium supplements. Symptoms and signs of Cushing's syndrome (CS) including easy bruising, proximal muscle weakness, and central obesity were subsequently detected (Fig 1). He denied any history of taking herbal medicine or exogenous steroids. The overnight 1-mg dexamethasone screening test for CS yielded a non-suppressible plasma cortisol level of 1308 (reference level $[R L],<50) \mathrm{nmol} / \mathrm{L}$. Paired 9am cortisol and adrenocorticotropic hormone (ACTH)

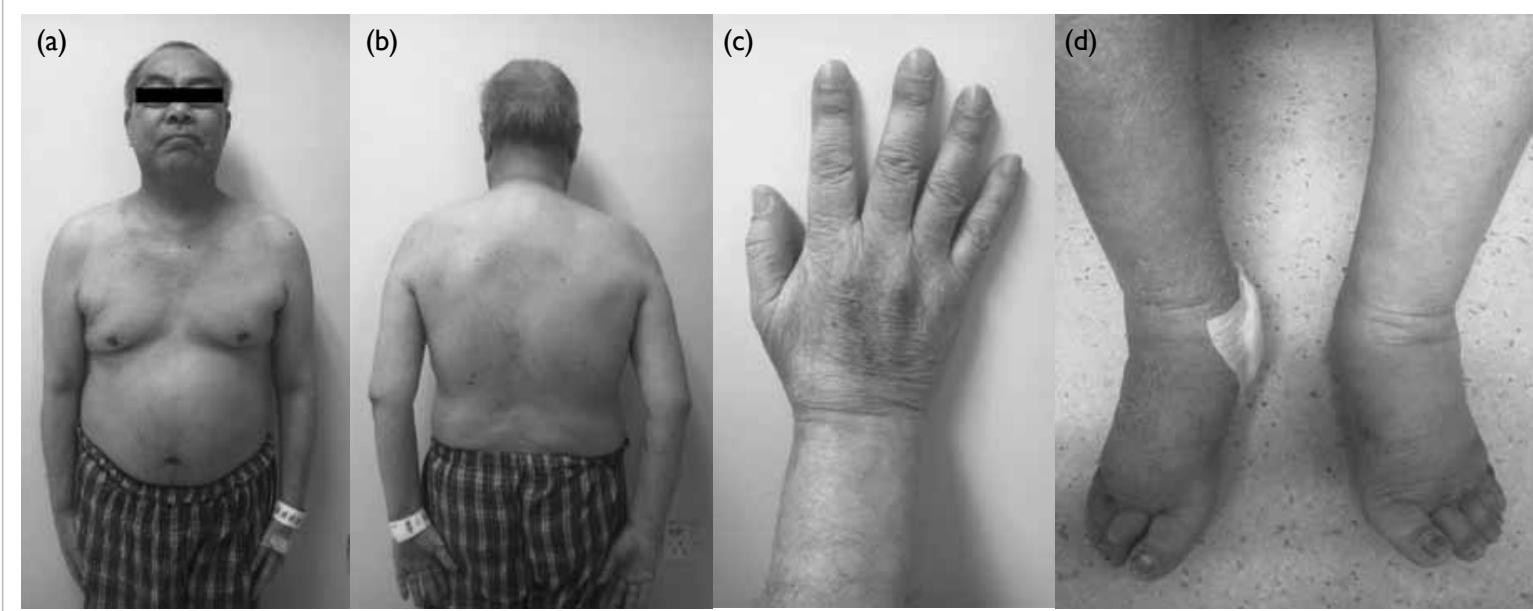

FIG I. Cushingoid features of the patient. (a) Patient's front showing moon face and central adiposity; (b) patient's back showing buffalo hump; (c) bruising over hand; (d) dependent oedema with poor wound healing over patient's feet 


\section{一名70歲庫欣氏症候群男性患者的罕見病因}

張潔婷、蘇詠儀、江碧珊、馬青雲、李傑輝、周振中

約有 $1 \%$ 的人口因不同原因服食外源性類固醇, 所以因外源性類固醇而 患上庫欣氏症候群（腎上腺皮質方進）很普遍。因胰腺神經內分泌腫 瘤而產生異位促腎上腺皮質激素, 從而出現內源性庫欣氏症候群很少 見, 早期和正確的診斷非常重要。臨床的高度敏鋭性和各個專科之間 的合作溝通對於診斷和醫治很關鍵。本文報告一個胰腺神經內分泌腫 瘤伴有肝轉移的異位促腎上腺皮質激素的病例。內分泌專科醫生能於 早期作出診斷、及時的手術切除, 以及隨後轉介至腫瘤科醫生, 令病 人直至病發後的 12 個月的治理結果仍然良好。
35-151 nmol/day). He also failed the confirmatory low-dose dexamethasone suppression test with a cortisol level of $997 \mathrm{nmol} / \mathrm{L}$ (RL, $<50 \mathrm{nmol} / \mathrm{L}$ ) after 2 days of dexamethasone loading. The peripheral corticotropin-releasing hormone $(\mathrm{CRH})$ stimulation test later established the diagnosis of ectopic ACTH CS, since both the ACTH and cortisol responses were flat after $\mathrm{CRH}$ injection. Ketoconazole was commenced at that juncture, which was 2 months after the patient's initial presentation.

Contrast computed tomography (CT) of the thorax and abdomen followed immediately, and revealed a well-defined ovoid cystic area (6.3 x 4.8 x $4.9 \mathrm{~cm}$ ) with an intralesional eccentric isodense mildly enhanced mural nodule in the body of pancreas that was consistent with pancreatic tumour, with enlarged lymph nodes posterior to the body of the organ (Figs 2a and 2b). Mild generalised osteoporosis was also noted. Positron emission tomography (PET) of the whole body 2 weeks later
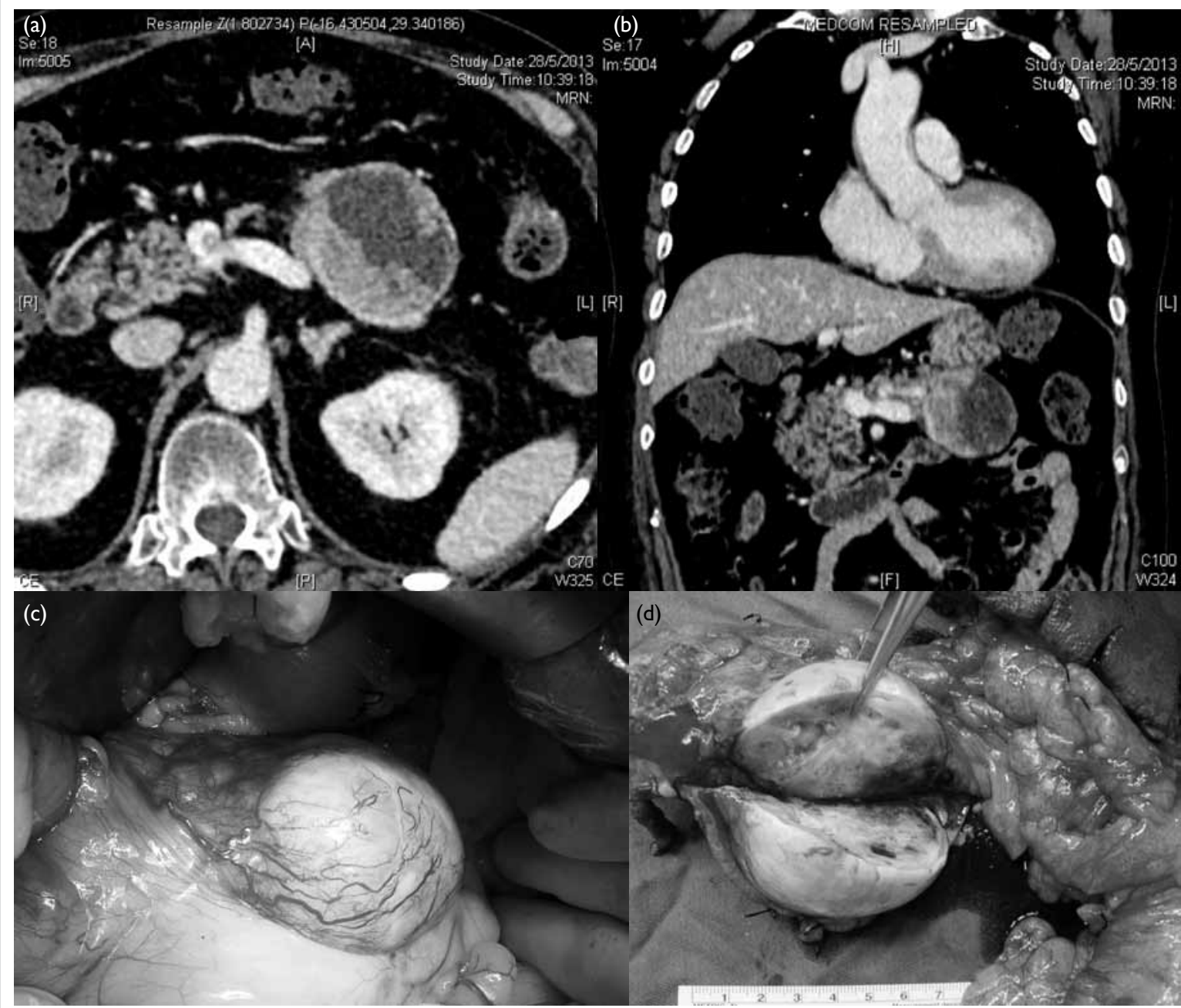

FIG 2. (a) Transverse view, and (b) reconstituted coronal view of the preoperative contrast computed tomography of the patient's thorax and abdomen showing a pancreatic tumour. (c) Intra-operative view and (d) surgical specimen of the pancreatic tumour 
showed a mildly hypermetabolic heterogeneous lesion in the body of the pancreas, compatible with the known pancreatic tumour. Also, there were mildly hypermetabolic lymph nodes in the peripancreatic region, possibly due to early nodal involvement. The serum CA19.9 level (a tumour marker of pancreatic cancer) was elevated ( $89 \mathrm{kIU} / \mathrm{L} ; \mathrm{RL},<18 \mathrm{kIU} / \mathrm{L}$ ).

The patient was referred to surgeons 3 months after initial presentation, and offered distal pancreatectomy with splenectomy (Figs 2c and 2d). Intra-operatively, a solitary $2-\mathrm{mm}$ nodule over the undersurface of segment III of liver, not identified in the preoperative $\mathrm{CT}$, was found and histologically confirmed to be metastatic neuroendocrine tumour (NET). Intra-operative ultrasound did not reveal any other liver lesions. There were no palpable lesions over whole length of small bowel or colon in the peritoneum or the omentum. Histology of the resected pancreatic mass confirmed the presence of malignant pancreatic NET (P-NET) with extrapancreatic extension and lymphovascular permeation. The tumour cells were diffusely positive for CK19, synaptophysin, and chromogranin. Staining for ACTH, gastrin, and pancreatic polypeptidase were focally positive, but staining for insulin, serotonin, somatostatin, and glucagon were all negative. The proliferative pool as assessed by Ki-67 was estimated to be approximately $15 \%$.

Postoperatively, ketoconazole was stopped, and the patient started taking replacement doses of hydrocortisone. He was then referred to an oncologist for further management in view of the metastatic nature of his disease (stage IV P-NET due to confirmed liver metastasis). One month after the operation, the patient experienced marked alleviation of his symptoms. He had no more oedema and the OHA requirements were significantly reduced.

\section{Discussion}

Cushing's syndrome due to exogenous steroids is common, as about $1 \%$ of the general populations use exogenous steroids for various indications. ${ }^{1}$ Ectopic ACTH secretion accounts for approximately $10 \%$ to $20 \%$ of all cases of CS. ${ }^{2}$ The leading cause is smallcell lung carcinoma, accounting for about $50 \%$ of the cases. Other less common tumours reported are pancreatic, bronchial, thymic, and thyroid medullary carcinoma. Certainly, P-NETs are rare and have an incidence of approximately 1/100 000 persons per year, and both genders appear equally prone. $^{3}$ Among the P-NETs, insulinoma, gastrinoma, glucagonoma, somatostatinoma, and VIPoma have all been reported. Other non-functioning islet neoplasms and other hormone-secreting (eg ACTH) tumours have also been published in case reports. ${ }^{4}$ Other than insulinoma, these P-NETs are generally malignant. Those that are ACTH-producing (account for approximately $1.2 \%$ of them) are particularly aggressive. ${ }^{4}$ Metastases, usually to the liver, are often observed in early phase, even before the presentation of CS. ${ }^{5}$ The 2- and 5-year survival rates of patients with P-NETs are about $40 \%$ and $16 \%$, respectively. ${ }^{6}$

Symptoms and signs from excess cortisol, followed by biochemical evaluation and subsequent imaging, as in our patient, are important in the timely diagnosis of functioning P-NETs. In our patient, both the screening and other confirmatory tests for CS established the diagnosis. Non-suppressible/high $\mathrm{ACTH}$ in the presence of high serum concentrations and urinary secretion of cortisol, coupled with flat ACTH and cortisol responses after provocative peripheral CRH stimulation test, strongly suggested the CS was due to an ectopic ACTH-secreting source rather than the pituitary.

Other than the peripheral CRH stimulation test which offers $86 \%$ sensitivity and $90 \%$ specificity for pituitary CS, ${ }^{7}$ high-dose dexamethasone suppression test (HDDST) and bilateral inferior petrosal sinus (IPS) sampling for ACTH are two other options for differentiating pituitary CS and ectopic ACTH CS. A positive HDDST, characterised by suppression of serum cortisol by $\geq 50 \%$ from baseline by $8 \mathrm{mg}$ of dexamethasone taken at $11 \mathrm{pm}$ the night before, offers $77 \%$ sensitivity and $60 \%$ specificity for CS. The rationale for the use of HDDST is based on the principle that pituitary tumours are only partially autonomous, retaining feedback mechanism at a higher set point than normal. Therefore, when enough dexamethasone is administered, ACTH and cortisol secretion can be suppressed. While for ectopic ACTH tumours, which are usually autonomous, production of hormones cannot be suppressed with dexamethasone. However, some benign ectopic tumours may be suppressible, while pituitary macroadenomas are often non-suppressible. ${ }^{7}$ Whilst IPS sampling is invasive, it is the most direct way to examine whether the pituitary is the source of excess ACTH. An IPS/periphery ACTH ratio of $>2.0$ correctly identifies CS with $95 \%$ sensitivity and $100 \%$ specificity. The sensitivity is further improved to $100 \%$ when CRH is administered using the cut-off of post-CRH IPS/periphery ratio of $>3.0 .^{8}$

In our case, immediate search for the ACTHsecreting source using CT and PET identified the pancreatic tumour promptly. Other imaging modalities commonly used in localising NETs include magnetic resonance imaging, endoscopic ultrasound, and somatostatin receptor scintigraphy. The source of ACTH in $30 \%$ to $50 \%$ of patients with ACTH-dependent CS is not localised by the conventional imaging modalities listed above. ${ }^{9}$ Newer imaging techniques such as fluorine-labelled dihydroxyphenylalanine $\left({ }^{18} \mathrm{~F}-\mathrm{DOPA}\right) \mathrm{PET} / \mathrm{CT}$ are now being used to localise occult sources, although the usefulness of some of them remains controversial. 
In a series of 17 patients, no advantage was seen with tumour localisation using $\left({ }^{18} \mathrm{~F}-\mathrm{DOPA}\right) \mathrm{PET} / \mathrm{CT}$ when compared with conventional imaging, while another study reported $100 \%$ localisation of ectopic ACTH-secreting NETs using ( ${ }^{18} \mathrm{~F}$-DOPA) PET/CT in three patients. ${ }^{9,10}$

Treatments for P-NETs include surgery, chemotherapy, radiotherapy, and interventional radiology techniques such as hepatic artery chemoembolisation. Surgery is the first-line option for resectable tumours and is also used for debulking metastatic tumours. Total hepatectomy with living donor transplantation has also been attempted for treating metastatic tumours. ${ }^{11}$ Somatostatin and its analogues have both antisecretory and antiproliferative effects. ${ }^{12}$ Although P-NETs are relatively radioresistant, recently developed peptide receptor radiotherapy employing radionuclidetargeted somatostatin receptor agonists for internal cytotoxic radiotherapy in somatostatin receptorexpressing NETs seem promising. ${ }^{12}$ Systemic therapies for unresectable tumours include sunitinib malate, a potent tyrosine kinase inhibitor with antiangiogenic effects, and everolimus, an inhibitor of mammalian target of rapamycin. ${ }^{12,13}$ After surgical resection of malignant P-NETs, Ki- $67>5 \%$ of tumour cells is a predictor of recurrence. ${ }^{5}$ Since our patient had a Ki-67 of approximately 15\%, oncological treatment will be needed, hence, the referral.

In conclusion, our patient with an ectopic ACTH-secreting P-NET presented with diabetes and hypertension, both of which are common chronic diseases worldwide. Due to the aggressive nature of this type of tumour and its histological findings, this patient will likely require further adjuvant treatments in the future. Ectopic ACTH CS can occur due to a wide spectrum of causes, and a combination of relevant biochemical tests and imaging are needed to establish the correct diagnosis. Timely referral to surgeons and/or oncologists is necessary. Symptoms of hormone excess are often the first hint suggesting the diagnosis of functioning P-NETs. Almost all P-NETs, except insulinoma, carry a high malignant potential. Expeditious and meticulous management involving collaboration between endocrinologists, surgeons, pathologists, and oncologists can be expected to provide the best outcomes for patients suffering from this rare disease.

\section{References}

1. Prague JK, May S, Whitelaw BC. Cushing's syndrome. BMJ 2013;346:f945.

2. Wajchenberg BL, Mendonca BB, Liberman B, et al. Ectopic adrenocorticotropic hormone syndrome. Endocr Rev 1994;15:752-87.

3. Eriksson B, Oberg K. Neuroendocrine tumours of the pancreas. Br J Surg 2000;87:129-31.

4. Ito T, Tanaka M, Sasano H, et al. Preliminary results of a Japanese nationwide survey of neuroendocrine gastrointestinal tumors. J Gastroenterol 2007;42:497-500.

5. Doppman JL, Nieman LK, Cutler GB Jr, et al. Adrenocorticotropic hormone-secreting islet cell tumors: are they always malignant? Radiology 1994;190:59-64.

6. Clark ES, Carney JA. Pancreatic islet cell tumor associated with Cushing's syndrome. Am J Surg Pathol 1984;8:917-24.

7. Reimondo G, Paccotti $P$, Minetto $M$, et al. The corticotrophin-releasing hormone test is the most reliable noninvasive method to differentiate pituitary from ectopic ACTH secretion in Cushing's syndrome. Clin Endocrinol (Oxf) 2003;58:718-24.

8. Invitti C, Pecori Giraldi F, de Martin M, Cavagnini F. Diagnosis and management of Cushing's syndrome: results of an Italian multicentre study. Study Group of the Italian Society of Endocrinology on the Pathophysiology of the Hypothalamic-Pituitary-Adrenal Axis. J Clin Endocrinol Metab 1999;84:440-8.

9. Pacak K, Ilias I, Chen CC, Carrasquillo JA, Whatley $\mathrm{M}$, Nieman LK. The role of [(18)F]fluorodeoxyglucose positron emission tomography and [(111)In]diethylenetriaminepentaacetate-D-Phe-pentetreotide scintigraphy in the localization of ectopic adrenocorticotropin-secreting tumors causing Cushing's syndrome. J Clin Endocrinol Metab 2004;89:2214-21.

10. Kumar J, Spring M, Carroll PV, Barrington SF, Powrie JK. 18Flurodeoxyglucose positron emission tomography in the localization of ectopic $\mathrm{ACTH}$-secreting neuroendocrine tumours. Clin Endocrinol (Oxf) 2006;64:371-4.

11. Blonski WC, Reddy KR, Shaked A, Siegelman E, Metz DC. Liver transplantation for metastatic neuroendocrine tumor: a case report and review of the literature. World J Gastroenterol 2005;11:7676-83.

12. Wiedenmann B, Pavel M, Kos-Kudla B. From targets to treatments: a review of molecular targets in pancreatic neuroendocrine tumors. Neuroendocrinology 2011;94:177-90

13. Hörsch D, Grabowski P, Schneider CP, et al. Current treatment options for neuroendocrine tumors. Drugs Today (Barc) 2011;47:773-86. 